\title{
A comparison, using X-ray micro-computed tomography, of the architecture of cancellous bone from the cervical, thoracic and lumbar spine using 240 vertebral bodies from 10 body donors
}

\author{
Guido Schröder ${ }^{1}$, Benjamin Jabke ${ }^{2}$, Marko Schulze $^{3}$, Andreas Wree ${ }^{3}$, Heiner Martin ${ }^{4}$, Olga Sahmel ${ }^{4}$, \\ Alexandra Doerell ${ }^{5}$, Claus Maximilian Kullen ${ }^{6}$, Reimer Andresen ${ }^{6}$, Hans-Christof Schober $^{7}$ \\ ${ }^{1}$ Clinic for Surgery, Department of Orthopedics and Trauma Surgery, Buetzow, ${ }^{2}$ Department of Internal Medicine, University Medical School \\ Rostock, Rostock, ${ }^{3}$ Institute of Anatomy, University Medical School Rostock, Rostock, ${ }^{4}$ Institute for Biomedical Engineering, University of Rostock, \\ Rostock-Warnemuende, ${ }^{5}$ Faculty of Medicine Carl Gustav Carus, Dresden, ${ }^{6}$ Institute of Diagnostic and Interventional Radiology/Neuroradiology, \\ Westkuestenklinikum Heide, Academic Teaching Hospital of the Universities of Kiel, Luebeck and Hamburg, Heide, ${ }^{7}$ Department of Internal Medicine \\ IV, Municipal Hospital Suedstadt Rostock, Academic Teaching Hospital of the University of Rostock, Rostock, Germany
}

\begin{abstract}
The vertebral trabecular bone has a complex three-dimensional microstructure with an inhomogeneous morphology. Correct identification and assessment of the weakest segments of the cancellous bone may lead to better prediction of fracture risk. The aim of this study was to compare cancellous bone from 240 vertebrae of the cervical, thoracic and lumbar spine of ten body donors with osteoporosis in regard to bone volume fraction (BVF), trabecular thickness, separation, trabecular number and degree of anisotropy, to ascertain why cervical vertebrae rarely fracture, even with severe osteoporosis. Samples were obtained from all vertebrae with a Jamshidi needle (8 Gauge). The investigations were performed with a micro-computed tomography (micro-CT) device (SKYSCAN 1172, RJL Micro \& Analytic GmbH, Karlsdorf-Neuthard, Germany). Existing vertebral fractures and the bone mineral density of the lumbar spine were assessed with quantitative CT. Regarding the micro-CT parameters, statistically significant differences were observed between the various sections of the spine. We found a higher BVF, trabecular number and trabecular thickness, as well as a lower trabecular separation of the cervical vertebrae compared to other vertebrae. In addition, the degree of anisotropy in the cervical spine is lower than in the other spinal column sections. These results are age and sex dependent. Thus, the cervical spine has special structural features, whose causes must be determined in further investigations.
\end{abstract}

Key words: Osteoporosis, Aging, X-ray microtomography, Spine

Received October 12, 2020; Revised December 6, 2020; Accepted December 7, 2020

Corresponding author:

Guido Schröder (iD

Clinic for Surgery, Department of Orthopedics and Trauma Surgery,

Buetzow 18246, Germany

E-mail: guido.schroeder1@gmx.net

\section{Introduction}

Osteoporosis is a common metabolic skeletal disorder characterized by decreased bone mass and deteriorated bone structure leading to increased susceptibility to fractures [1].

Fractures due to osteoporosis occur especially in the thoracic vertebrae $7,8,12$, and the lumbar vertebra 1 [2]. 
In only very few cases osteoporotic fractures have been reported above the fourth thoracic vertebra or in the cervical spine [3,4] and limited reports are available investigating cervical bone structure for osteoporosis [5].

The load-bearing capacity of a section of the spinal column depends on the material properties of the vertebral body and on its geometric dimensions. Since the material properties of bone tissue are, in the broadest sense, given, the dimensions of the vertebral bodies can be viewed as the result of an adaptive process to the external and internal loads (body weight, muscle activity, pre-tensioning of the ligament structures, and externally applied forces). With increasing size of the vertebral bodies, their resilience also increases [6]. The position of the lumbar vertebrae alone puts more strain on them, as the load acting on the vertebral bodies increases in the caudal direction [7]. The spine, however, is not a rigid structure and is not statically but dynamically loaded, also not with individual forces or moments, but rather with dynamic combination loads (flexion, compression, torsion, shear) in different spatial directions. The segments of human movement react visco-elastically in a non-linear fashion to dynamic loads and can be described by the course of a hysteresis [8]. For a small deflection, only comparatively small forces are necessary; with larger deflections, elastic restoring forces develop due to the complexity of the present system, caused by the ligamentous apparatus and the muscles $[9,10]$. This suggests that cervical vertebrae adapted micro-architecturally due to the great mobility. In addition, the position of the momentary axis of rotation in the cervical spine changes permanently, which in turn determines the response of the vertebral body to the momentary loads [9].

Osteoporotic fractures are the result of changes in the trabecular structure such as loss or thinning of the trabeculae as well as changes in the cortical shell.

There are few studies on changes in the cervical, thoracic or lumbar spine that describe various structural characteristics that could be responsible for the low incidence of cervical spine fractures in osteoporosis patients [11-13]. In the present study 240 vertebrae from 10 human cadavers were examined in regard to their microarchitecture parameters in order to find explanations for this characteristic.

\section{Materials and Methods}

\section{Design and group allocation}

The study was designed as a multicenter radiological and anatomical investigation of an intervention group. Group allocation was based on the position of the vertebrae in the individual portions of the spine.

\section{Recruitment and ethics}

All of the body donors included in the study had provided their written consent during their lifetime and made their bodies available for anatomical and clinical research after their demise. All cadavers were obtained from the body donor program at the Medical Faculty of the University of Rostock. The methods used to obtain human tissue were humane and decent and met the ethical standards of the Declaration of Helsinki. The study was approved by the regional ethics committee for medical research (registration number A2017-0072).

\section{Inclusion and exclusion criteria}

The inclusion criterion for the investigation was the presence of 24 free vertebrae in each extracted spine. Exclusion criteria were bone metastases, tumors, Paget's disease, fusion of vertebrae or the formation of block vertebrae and previous operations with foreign material in the spine. If the sample could not be harvested in one connected piece, contained compact bone or was not complete due to a prosthesis, it was excluded.

\section{Extraction of the spine and cancellous bone}

About 10-12 liters of a 96\% ethanol solution (Ethanol 96\%, MEK denatured, Walter-CMP, Kiel, Germany) at 0.5 bar were perfused into the cadaver through the left femoral artery and then stored in a $0.5 \%$ aqueous phenol solution in free-floating form in cuvettes, in order to prevent air pockets in the spinal canal or vessel stumps. Through preparation we aimed to conserve the swinging of the vertebral column in order to be able to calculate forces. After exposure of the superficially migrated spinal muscles (the trapezius muscle, the rhomboid major and rhomboid minor muscles, the levator scapulae muscle, and the latissimus dorsi muscle) and the autochthonous spinal muscles, the ribs were separated over a breadth of about four inches in the paravertebral aspect. The separation was performed in a way that the ligaments of the spine stayed fully intact and the short deep local spinal 

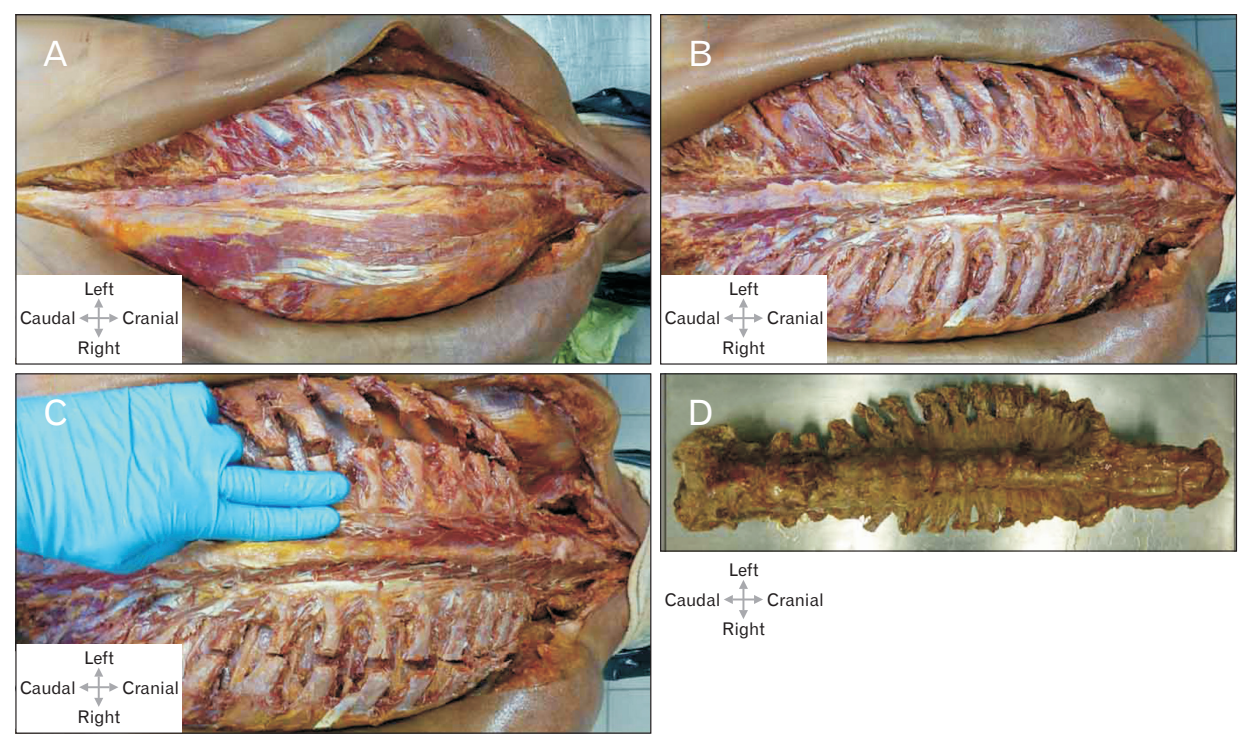

Left

Caudal $\underset{t}{\stackrel{4}{\longrightarrow}}$ Cranial

Right

Fig. 1. (A) Skin incision along the spinous process from the sacrum to the occiput (superior nuchal line); secondary spinal muscles (including the trapezius muscle, the latissimus dorsi, major and minor rhomboid, superior and inferior posterior serratus muscles), skin and subcutaneous fatty tissue were shifted laterally. Left: the subsequent lateral tract of the autochthonous spinal muscles was removed and the ribs were exposed. (B) The spinal muscles have been largely removed; the intercostal spaces have been emptied in the paravertebral aspect. The pleura has been separated from the inside of the ribs, the atlanto-occipital joint is exposed and the capsular ligaments have been transected. The cervical spine has been mobilized in the retropharyngeal space, the scalenemuscles have been transected. (C) Transection of all ribs about 1.5 inches wide in the paravertebral aspect of the spinous processes, along the scapular line. Separation of the parietal pleura from the inside of the ribs, wedge-shaped incision in the sacrum. (D) Complete specimen of the spine.

muscles (the long and short rotator muscles, interspinal muscles, and intertransverse muscles) were also fully preserved. Transection of the posterior atlantooccipital membrane from the dorsal aspect was followed by disarticulation of the atlantooccipital joint. The prevertebral muscles (musculus longus capitis, musculus rectus capitis anterior, lateralis, superior, posterior minor, obliquus capitis superior) between the base of the skull and the ventral portion of the cervical spine were transected and the ventral vertebrae were bluntly separated from the tissue of the throat through the retropharyngeal space. The parietal pleura was undermined bluntly from the ventral vertebral bodies. The pairwise branches of the aorta and venous stems (posterior intercostal arteries and intercostal vein) were separated and the subsequent portion of the spine to the psoas muscle was exposed. In the region of the sacrum, approximately at the level of the joint space of the sacroiliac joint, a saw cut was made on both sides and the entire spine was removed from the dorsal aspect (Fig. 1). Great effort was made to minimize mechanical manipulation of the spine in order to preserve the natural curvature (lordosis, kyphosis and scoliosis) of the respective portions. Therefore, the specimens were preserved in free-floating form in $70 \%$ ethanol at $4^{\circ} \mathrm{C}$ in recyclable synthetic tubes until imaging in- vestigations were performed and cancellous bone was taken by puncture. The latter was performed from the ventral aspect in the middle of the vertebral body and the correct position was checked on X-ray investigations.

\section{Diagnostic imaging}

\section{Computed tomography and quantitative computed tomography}

Pre-existing fractures or significant bone disease (e.g., bone metastases) in the entire spine was assessed on highresolution computed tomography (CT) images (GE Revolution EVO/64 rows/128 slice detector/thickness $0.625 \mathrm{~mm}$ slices). In order to analyze the specimens as realistically as possible on imaging investigations, conventional X-rays of the spines were performed under standardized conditions in an airless setup in a water phantom. To simulate the soft tissue mantle, which is necessary to adjust the CT-results, we used an economical recyclable system consisting of a commercially available plexiglass phantom with a diameter of $25 \mathrm{~cm}$, a height of $125 \mathrm{~cm}$ (tube of hard polyvinylchloride, Fig. 2A) and a homogeneous solid body. This resulted in a simulated soft tissue volume in the homogeneous ambient 

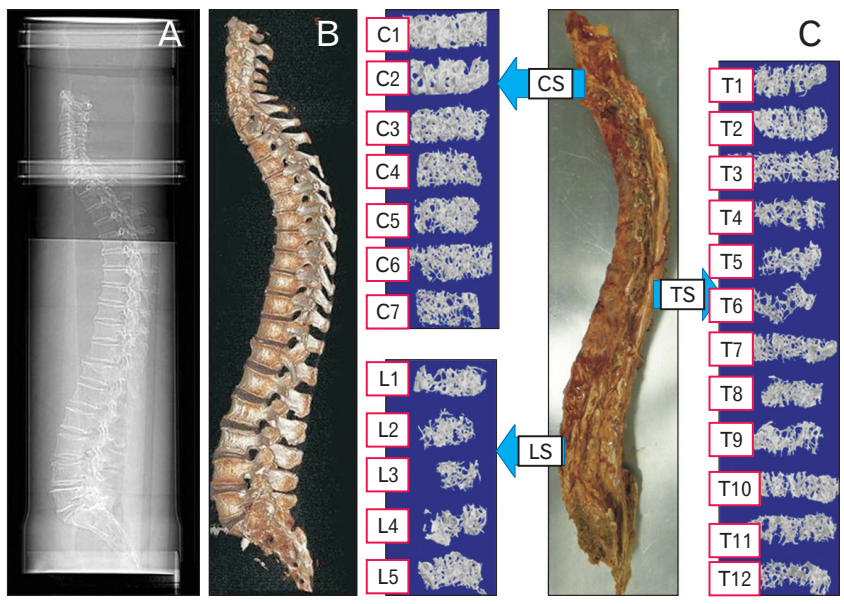

Fig. 2. (A) Spine in a water bath, registration of vertebral deformities on the lateral image. (B) Three-dimensional reconstruction to visualize the overall anatomy of the spine. (C) Prepared spinal column with reconstructed cancellous bone cylinders in micro-computed tomography. CS, cervical spine; LS, lumbar spine; TS, thoracic spine.

medium water to prevent air inclusions within the cancellous bone. The tubes were provided with a lip seal ring at one end, which could be permanently closed with a solid plug. The opposite end had a double bell coupling. After filling, this end was closed with a perforated solid plug that could be opened again so the entire system could be used several times. The tube was filled with water, without air, through a drill hole in the lid and then sealed by waterproof synthetic material.

The spines were loosely fixed in the longitudinal axis by suspension devices attached to the inner wall of the tube (Fig. 2A) [14]. On the exterior we marked the positioning of the spine to predict the alignment in the scan. Spinal deformities [15] were visualized on a scanogram. Three-dimensional (3D) reconstruction was performed at an external workstation to visualize the entire anatomy of the spine (GE AW-Server Version 2.0. Measurement of spines were outperformed in GE Centricity RIS-i Version 5.0; GE Healthcare, Frankfurt am Main, Germany) (Fig. 2B).

Bone mineral density was determined by quantitative computed tomography (QCT; GE Revolution EVO/64-line row/128 slices CT, in combination with Mindways Software 3D Volumetric QCT Spine, Austin, TX, USA). As usual, the bone mineral content of cancellous bone was determined in a volume block at the level of the first, second, and third lumbar vertebrae.

\section{Micro-computed tomography images and evaluation of} microarchitecture

Samples from the ventral medial side were obtained from 240 vertebral bodies with the aid of a Jamshidi needle (8 gauge) and prepared for further investigation in a damp cloth placed in an Eppendorf reaction vessel $(1.5 \mathrm{ml})$. Investigations on the bone cylinders were performed using a microCT device (SKYSCAN 1172, RJL Micro \& Analytic Private Ltd. Co., Karlsdorf Neuthart, Germany). Flat-field correction and comparisons with phantoms (reference) of $0.25 \mathrm{~g} / \mathrm{cm}^{3}$ and $0.75 \mathrm{~g} / \mathrm{cm}^{3}$ thickness were conducted. The settings for the scanning process were established as follows: filter AI 0.5, resolution $640 \times 512$ pixels, pixel size $19.9 \mu \mathrm{m}$, nominal isotropic voxel size of $35 \mathrm{~mm}$ (field of view $70 \mathrm{~mm}$, X-ray source $100 \mathrm{kV}, 100 \mathrm{~mA}$ ).

In order to exclude the cortical component of the vertebral body, the trabecular region of interest was defined manually. The following parameters of trabecular microarchitecture were measured: bone volume fraction (BVF, measures the ratio of bone volume to total volume and is therefore a parameter for bone density, as percentage \%), trabecular bone thickness (Tb.Th, describes the thickness of the trabecular, measured in $\mu \mathrm{m}$ ), trabecular separation (Tb.Sp, measured in $\mu \mathrm{m}$ ), degree of anisotropy (DA, $0=$ isotropic; $1=$ anisotropic) and the trabecular number (Tb.N). Fig. $2 \mathrm{C}$ illustrates the bone cylinders of the micro-CT.

\section{Statistics}

IBM SPSS Statistics for Windows, Version 23.0 (IBM Co., Armonk, NY, USA) was used for data analysis. Quantitative characteristics were expressed as means $(M)$, standard deviation (SD), and numbers (n) of available observations, using the interval of $\mathrm{M} \pm \mathrm{SD}$. The Kruskal-Wallis test or the one-way ANOVA was used for group comparisons. This was selected according to the effect of the Shapiro-Wilk test on normal distribution. In the event of significant results, we performed pairwise comparisons or a post-hoc test. We used the Mann-U-Whitney rank-sum test to compare two groups for non-normally distributed values. On the other hand, the independent $t$-test was used to compare two groups with normally distributed values. Correlation analyses were also performed depending on the scale level. All $P$-values are the result of two-sided statistical tests. The level of significance was set to $P<0.05$. 
Table 1. Description of cases used in this study

\begin{tabular}{lc}
\hline \multicolumn{1}{c}{ Medical history } & Overall group $(\mathrm{n}=10)$ \\
\hline Age $(\mathrm{yr})$ & $81.3 \pm 7.9$ \\
Sex $($ male/female) & $4 / 6$ \\
Body mass index $\left(\mathrm{kg} / \mathrm{m}^{2}\right)$ & $20.8 \pm 4.6$ \\
Bone mineral density $\left(\mathrm{mg} / \mathrm{cm}^{3}\right)^{*}$ & $54.5 \pm 20.0$ \\
Segments excluded & $\mathrm{C} 1-\mathrm{L} 5$ \\
Vertebral body fractures $(\mathrm{n})$ & 14 \\
Total number of vertebrae & 240 \\
\hline
\end{tabular}

Values are presented as mean \pm SD or number only. $80-110 \mathrm{mg} / \mathrm{cm}^{3}$, low risk of fracture; $50-80 \mathrm{mg} / \mathrm{cm}^{3}$, moderately increased risk of fracture; $<50 \mathrm{mg} / \mathrm{cm}^{3}$, markedly increased risk of fracture. ${ }^{*}$ Quantitative computed tomography measurements.

\section{Results}

Trabecular bone samples were taken from 10 human cadavers ( 6 females, 4 males) with ages ranging from 73 to 102 years (mean 83.3, SD 7.9 years). Height varied from 1.47 to $1.76 \mathrm{~m}$ (mean 1.63 , SD $0.10 \mathrm{~m}$ ) with a body weight of 31.1 to $93.7 \mathrm{~kg}$ (mean 55.9, SD $16.7 \mathrm{~kg}$ ). Due to data protection laws, the available medical data were limited to the immediate cause of death, previous causes, and other major diseases that had contributed to death; these data were entered in the donors' death certificates. The height, body weight, and general constitution of the donors were registered prior to perfusion fixation. Table 1 provides a summary of the donors' medical history.

\section{Quantitative computed tomography}

The mean bone mineral density of the 10 spines, measured at the lumbar vertebrae 1 to 3 , was $54.5 \pm 20.0 \mathrm{mg} / \mathrm{cm}^{3}$ (range, 24.2-87.5), which indicates apronounced osteoporosis (values below $80 \mathrm{mg} / \mathrm{cm}^{3}$ are considered to be a sign of osteoporosis, values below $60 \mathrm{mg} / \mathrm{cm}^{3}$ reflect a higher risk of fractures) $[16,17]$. Table 1 summarizes additional data on the numbers and shapes of vertebral fractures based on the registered vertebral deformities. The correlation between number of fracture and bone density was very significant $(\mathrm{r}=-0.808, P=0.005)$.

\section{Micro-computed tomography}

\section{Group comparison of the spinal sections}

Variation in cancellous bone architecture with spinal level is presented in Fig. 3. Lumbar vertebrae have a significantly lower BVF versus the cervical spine (Fig. 3A). A pairwise comparison of BVF revealed a statistically very significant difference $(P=0.006)$ between the cervical and thoracic spine, and a highly significant difference $(P<0.001)$ between the cervical and lumbar spine. Comparison of the thoracic and lumbar spine revealed no significant difference $(P>0.05)$. Significantly thicker trabeculae are found in the cervical vertebrae as to in the thoracic and lumbar vertebrae (Fig. 3B). A pairwise comparison of Tb.Th revealed a very significant difference between the cervical and thoracic spine $(P=0.007)$ as well as between the cervical and lumbar spine $(P=0.004)$. The difference between the thoracic and lumbar spine was contrarily not significant $(P>0.05)$. Tb.Sp comparison yielded a highly significant difference $(P<0.001)$ between the various sections of the spine, which was also evident in the comparison of the cervical and thoracic spine $(P<0.001)$ and the cervical and lumbar spine $(P<0.001)$. In contrast, the difference between the thoracic and lumbar spine was not significant $(P>0.05)$.

Cervical vertebrae have a significantly lower DA than thoracic and lumbar vertebrae $(P=0.018)$, but on the other hand DA did not differ significantly between the thoracic and lumbar spine $(P>0.05)$. Finally, cervical vertebrae show significantly more trabecular than thoracic and lumbar vertebrae (Fig. 3E). A pairwise comparison of the values showed a highly significant difference between the cervical and thoracic spine, and the cervical and lumbar spine $(P<0.001)$, but no significant difference was noted between the thoracic and lumbar spine $(P>0.05)$. Table 2 summarize the results. The BVF correlates with TB.N ( $\mathrm{r}=0.668, P=0.035)$. A statistical trend is obtained by comparing the values of TB.N and the age of the body donors $(r=-0.619, P=0.056)$. The BMD determined in the qCT also corresponds with TB.N measured in the $\mathrm{mCT}$ ( $\mathrm{r}=0.804, P=0.005)$. The Tb.Sp increases if the BMD decreases $(r=-0.838, P=0.002)$, although the BVF and the Tb.Th correlate in the same direction $(r=0.877, P=0.001)$.

\section{Subgroup analysis}

In a subgroup analysis sex and age were considered separately. Significantly higher BVF in cervical vertebrae compared to thoracic and lumbar vertebrae can be seen (Table 2, Fig. 3A).

Cervical vertebrae of women and men as well as those under 80 years of age exhibit significantly thicker trabeculae than the lumbar vertebrae (Fig. 3B). In regards to this parameter a significant difference in the cervical and thoracic vertebrae of persons over 80 years of age was found. In contrast, the comparison of the values between the cervical and 
A

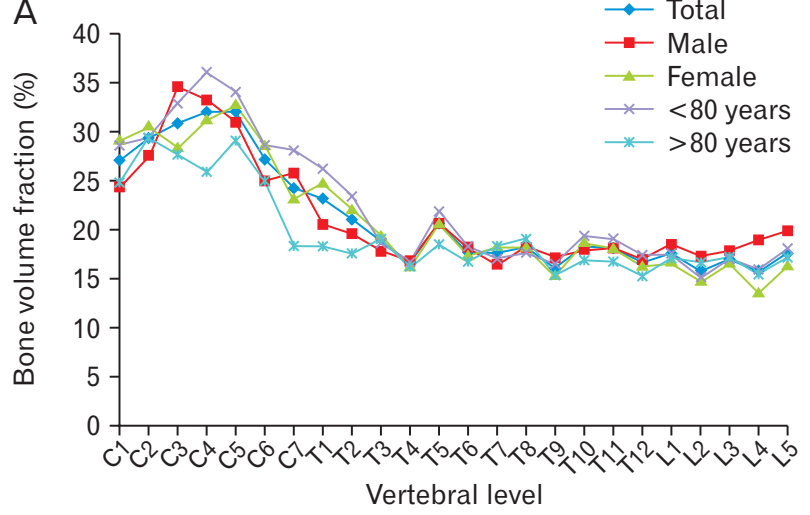

C
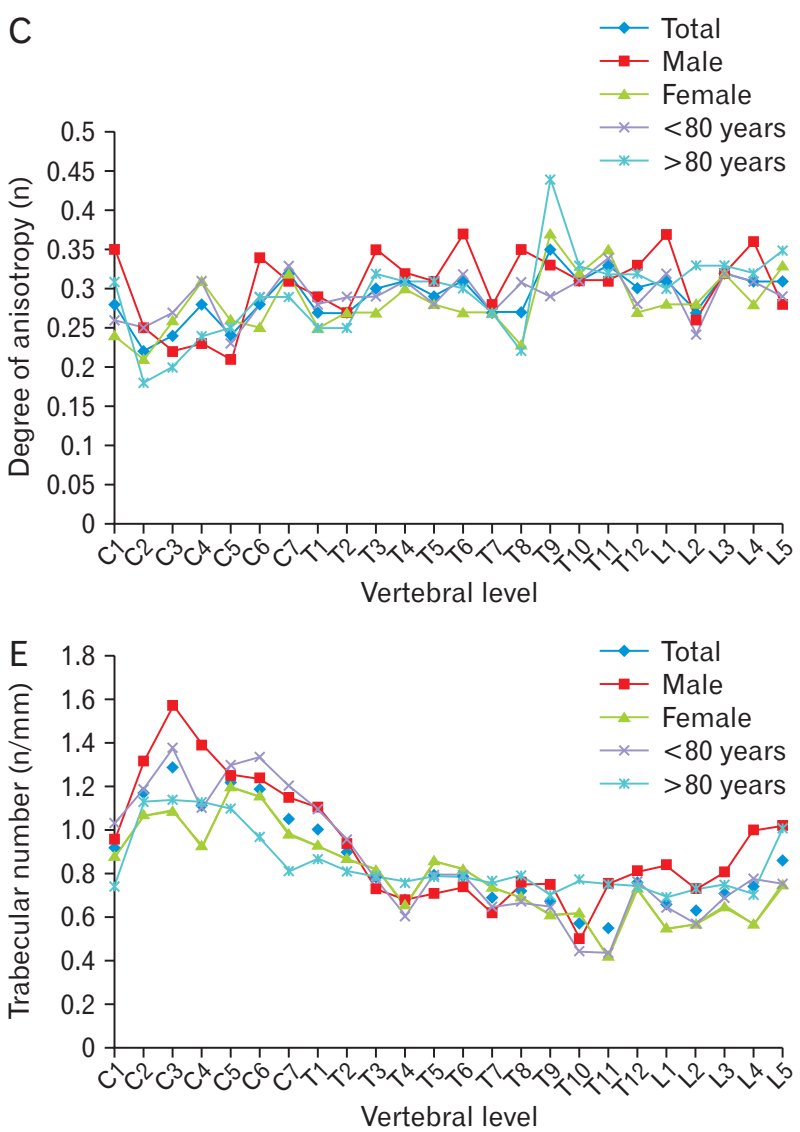

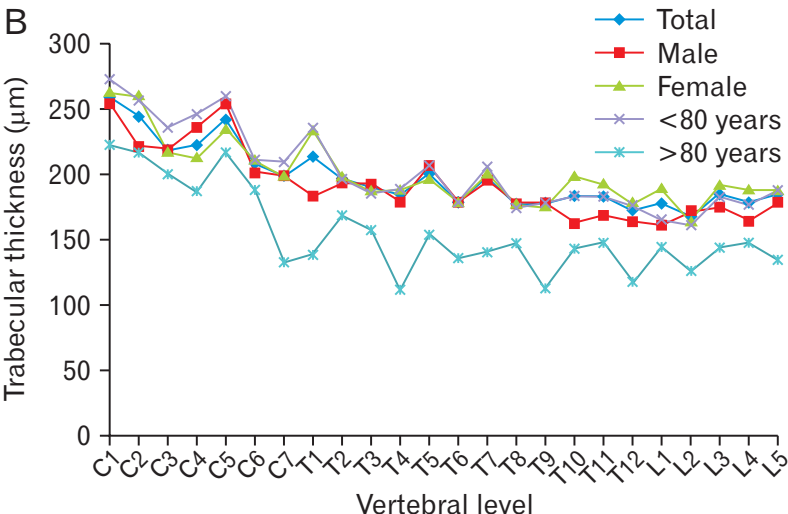

D $\rightarrow$ Total
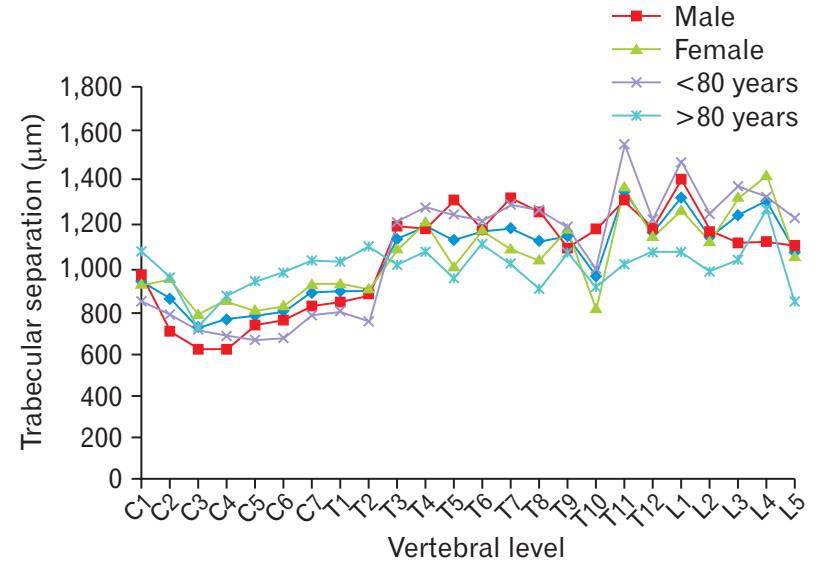

Fig. 3. (A) Regional variation in vertebral trabecular BVF. Cervical vertebrae exhibit significantly higher BVF in relation to thoracic and lumbar vertebrae (Kruskal-Wallis-test, $P$-values in Table 2). The subgroup analysis using the Mann-Whitney U-test showed no significant difference between women and men or between those over and under 80 years of age $(P>0.05)$. (B) Regional variation in Tb.Th. Cervical vertebrae exhibit significantly higher Tb.Th in relation to thoracic and lumbar vertebrae. Only in the over-80s is there no significant difference between the cervical and lumbar vertebrae (Kruskal-Wallis-test, $P$-values in Table 2). The subgroup analysis using the Mann-Whitney U-test showed no significant difference between women and men or between those over and under 80 years of age $(P>0.05)$. (C) Regional variation in DA. Cervical vertebrae exhibit significantly lower DA in relation to thoracic and lumbar vertebrae (ANOVA, post-hoc LSD test, $P$-values in Table 2). The subgroup analysis using the independent t-test showed a significant difference between women and men $(P=0.042)$ and no significant difference between those over and under 80 years of age $(P>0.05)$. (D) Regional variation in Tb.Sp. Cervical vertebrae exhibit significantly lower Tb.Sp in relation to thoracic and lumbar vertebrae (ANOVA, post-hoc LSD test, $P$-values in Table 2). The subgroup analysis using the independent $\mathrm{t}$-test showed no significant difference between women and men or between those over and under 80 years of age $(P>0.05)$. (E) Regional variation in Tb.N. Cervical vertebrae exhibit significantly higher Tb.N in relation to thoracic and lumbar vertebrae (ANOVA, post-hoc LSD test, $P$-values in Table 2). The subgroup analysis using the independent $\mathrm{t}$-test showed no significant difference between women and men or between those over and under 80 years of age $(P>0.05)$. BVF, bone volume fraction; DA, degree of anisotropy; Tb.N, trabecular number; Tb.Sp, trabecular separation; Tb.Th, trabecular bone thickness. 
Table 2. Descriptive statistics for micro-computed tomography parameters

\begin{tabular}{|c|c|c|c|c|c|c|c|c|}
\hline \multirow{3}{*}{$\begin{array}{c}\text { Architectural } \\
\text { measure }\end{array}$} & \multirow{3}{*}{ Group } & \multicolumn{4}{|c|}{ Spinal sections } & \multicolumn{3}{|c|}{ Group comparison } \\
\hline & & & & & & CS vs. TS & CS vs. LS & TS vs. LS \\
\hline & & Total & CS & TS & LS & $P$-value & $P$-value & $P$-value \\
\hline \multirow[t]{5}{*}{ BVF (\%) } & Total & $21.20 \pm 5.55$ & $28.94 \pm 2.94$ & $18.53 \pm 2.08$ & $16.73 \pm 0.94$ & $0.006^{\mathrm{P}}$ & $<0.001^{\mathrm{P}}$ & $0.458^{\mathrm{P}}$ \\
\hline & Male & $21.31 \pm 5.41$ & $28.74 \pm 4.15$ & $18.15 \pm 1.34$ & $18.49 \pm 1.00$ & $0.001^{\mathrm{P}}$ & $0.031^{\mathrm{P}}$ & $1.000^{\mathrm{P}}$ \\
\hline & Female & $21.12 \pm 5.92$ & $29.08 \pm 3.06$ & $18.79 \pm 2.68$ & $15.56 \pm 1.38$ & $0.009^{\mathrm{P}}$ & $<0.001^{\mathrm{P}}$ & $0.327^{\mathrm{P}}$ \\
\hline & $<80 \mathrm{yr}$ & $22.23 \pm 6.47$ & $31.08 \pm 3.20$ & $19.34 \pm 3.00$ & $16.75 \pm 1.18$ & $0.006^{\mathrm{P}}$ & $<0.001^{\mathrm{P}}$ & $0.458^{\mathrm{P}}$ \\
\hline & $>80 \mathrm{yr}$ & $19.65 \pm 4.55$ & $25.74 \pm 3.74$ & $17.32 \pm 1.39$ & $16.72 \pm 0.80$ & $0.004^{\mathrm{P}}$ & $0.005^{\mathrm{P}}$ & $1.000^{\mathrm{P}}$ \\
\hline \multirow[t]{5}{*}{ Tb.Th $(\mu \mathrm{m})$} & Total & $198 \pm 25$ & $228 \pm 22$ & $188 \pm 12$ & $179 \pm 7$ & $0.007^{\mathrm{P}}$ & $0.004^{\mathrm{P}}$ & $1.000^{\mathrm{P}}$ \\
\hline & Male & $193 \pm 28$ & $227 \pm 23$ & $182 \pm 14$ & $170 \pm 7$ & $0.008^{P}$ & $0.001^{\mathrm{P}}$ & $0.485^{\mathrm{P}}$ \\
\hline & Female & $201 \pm 25$ & $228 \pm 25$ & $193 \pm 16$ & $184 \pm 12$ & $0.010^{\mathrm{P}}$ & $0.010^{\mathrm{P}}$ & $1.000^{\mathrm{P}}$ \\
\hline & $<80 \mathrm{yr}$ & $203 \pm 32$ & $242 \pm 25$ & $191 \pm 18$ & $175 \pm 11$ & $0.010^{\mathrm{P}}$ & $0.001^{\mathrm{P}}$ & $0.535^{\mathrm{P}}$ \\
\hline & $>80 \mathrm{yr}$ & $156 \pm 33$ & $195 \pm 31$ & $140 \pm 18$ & $140 \pm 9$ & $0.018^{\mathrm{P}}$ & $0.056^{\mathrm{P}}$ & $1.000^{\mathrm{P}}$ \\
\hline \multirow[t]{5}{*}{ Tb.Sp $(\mu \mathrm{m})$} & Total & $1,017 \pm 190$ & $789 \pm 77$ & $1,080 \pm 134$ & $1,185 \pm 108$ & $<0.001^{\mathrm{L}}$ & $<0.001^{\mathrm{L}}$ & $0.102^{\mathrm{L}}$ \\
\hline & Male & $1,014 \pm 237$ & $719 \pm 120$ & $1,129 \pm 157$ & $1,152 \pm 129$ & $<0.001^{\mathrm{L}}$ & $<0.001^{\mathrm{L}}$ & $0.767^{\mathrm{L}}$ \\
\hline & Female & $1,019 \pm 187$ & $836 \pm 66$ & $1,048 \pm 155$ & $1,207 \pm 152$ & $0.003^{\mathrm{L}}$ & $<0.001^{\mathrm{L}}$ & $0.037^{\mathrm{L}}$ \\
\hline & $<80 \mathrm{yr}$ & $1,047 \pm 284$ & $707 \pm 68$ & $1,139 \pm 223$ & $1,301 \pm 107$ & $0.012^{\mathrm{P}}$ & $0.001^{\mathrm{P}}$ & $0.514^{\mathrm{P}}$ \\
\hline & $>80 \mathrm{yr}$ & $974 \pm 108$ & $913 \pm 114$ & $993 \pm 71$ & $1,011 \pm 155$ & & & \\
\hline \multirow[t]{5}{*}{ DA (n) } & Total & $0.29 \pm 0.03$ & $0.27 \pm 0.03$ & $0.30 \pm 0.03$ & $0.31 \pm 0.02$ & $0.018^{\mathrm{L}}$ & $0.018^{\mathrm{L}}$ & $0.590^{\mathrm{L}}$ \\
\hline & Male & $0.30 \pm 0.05$ & $0.27 \pm 0.06$ & $0.32 \pm 0.03$ & $0.32 \pm 0.05$ & & & \\
\hline & Female & $0.28 \pm 0.04$ & $0.26 \pm 0.04$ & $0.29 \pm 0.04$ & $0.30 \pm 0.03$ & & & \\
\hline & $<80 \mathrm{yr}$ & $0.29 \pm 0.03$ & $0.28 \pm 0.03$ & $0.30 \pm 0.02$ & $0.29 \pm 0.03$ & & & \\
\hline & $>80 \mathrm{yr}$ & $0.29 \pm 0.06$ & $0.25 \pm 0.05$ & $0.30 \pm 0.06$ & $0.33 \pm 0.02$ & $0.038^{\mathrm{L}}$ & $0.017^{\mathrm{L}}$ & $0.395^{\mathrm{L}}$ \\
\hline \multirow[t]{5}{*}{ Tb.N (n/mm) } & Total & $0.85 \pm 0.22$ & $1.13 \pm 0.12$ & $0.74 \pm 0.13$ & $0.72 \pm 0.09$ & $<0.001^{\mathrm{L}}$ & $<0.001^{\mathrm{L}}$ & $0.759^{\mathrm{L}}$ \\
\hline & Male & $0.93 \pm 0.27$ & $1.27 \pm 0.19$ & $0.76 \pm 0.15$ & $0.88 \pm 0.13$ & $<0.001^{\mathrm{L}}$ & $<0.001^{\mathrm{L}}$ & $0.173^{\mathrm{L}}$ \\
\hline & Female & $0.80 \pm 0.21$ & $1.05 \pm 0.12$ & $0.73 \pm 0.14$ & $0.61 \pm 0.08$ & $<0.001^{\mathrm{L}}$ & $<0.001^{\mathrm{L}}$ & $0.106^{\mathrm{L}}$ \\
\hline & $<80 \mathrm{yr}$ & $0.86 \pm 0.28$ & $1.22 \pm 0.13$ & $0.72 \pm 0.20$ & $0.70 \pm 0.08$ & $<0.001^{\mathrm{L}}$ & $<0.001^{\mathrm{L}}$ & $0.704^{\mathrm{L}}$ \\
\hline & $>80 \mathrm{yr}$ & $0.84 \pm 0.15$ & $1.00 \pm 0.17$ & $0.78 \pm 0.04$ & $0.78 \pm 0.14$ & $0.088^{\mathrm{P}}$ & $0.016^{\mathrm{P}}$ & $0.776^{\mathrm{P}}$ \\
\hline
\end{tabular}

Values are presented as mean \pm SD. CS, cervical spine; TS, thoracic spine; LS, lumbar spine; BVF, bone volume fraction; Tb.Th, trabecular bone thickness; Tb.Sp, trabecular separation; DA, degree of anisotropy; Tb.N, trabecular number; ${ }^{\mathrm{P}}$, pairwise comparison; ${ }^{\mathrm{L}}$, post-hoc LSD test.

thoracic spine as well as between the thoracic and lumbar spine showed no significant difference $(P>0.05)$. The Tb.Sp increases from cervical to caudal in women, men and also in persons under 80 years of age, whereas in persons over 80 years of age no significant difference between the spinal sections is observed (Table 2). The DA is not significantly different in the spinal sections in women, men and also in persons under 80 years of age $(P>0.05)$. In people aged over 80 years, the difference between cervical and thoracic $(P<0.038)$ along with between cervical and lumbar spine $(P<0.017)$ is significantly different. No significant difference was seen between the thoracic and lumbar spine $(P>0.05)$. The group of males has a significantly higher degree of anisotropy compared to the group of females regarding the trabecular structure.

In addition, cervical vertebrae of women, men and people under 80 years of age have significantly more trabecular than the thoracic and lumbar vertebrae (Fig. 3E). In people over 80 years significant difference $(P=0.016)$ was only found between the cervical and lumbar spine.

\section{Discussion}

\section{Discussion of results}

The present investigation allowed a comparison of trabecular bone from all sections of the human spine, obtained from 10 body donors aged 73 to 102 years. All of the investigated probands had osteoporosis on bone densitometry.

In case of reduced bone density, vertebral body fractures were also found. These mainly concern T7, 8 and 12 and L1 [2].

A possible explanation for this fracture distribution along the spine could be the predominant curvature of the spine $[18,19]$. The turning point of the thoracic kyphosis is found in the middle area of the thoracic spine (T7, T8). Due to the increased curvature, higher bending moments and compression forces occur. This theory is also supported by the fact that an increase in the radius of curvature, equated with more severe kyphosis, which forms in the course of life and is of particular importance in osteoporosis, results in increased bending stress. The increased risk of fractures in the transi- 
tion T12 - L1 can also be explained by increased mobility in the lumbar vertebral area and the resulting higher compression loads [19]. According to the current state of knowledge, it is assumed that the overall mobility in flexion/extension decreases with increasing age [20-22]. This could contribute to local changes in the micro-architecture. No fractures were discovered in the cervical spine (CS) in the present examination.

Above T4, especially in the CS, osteoporotic fractures are only described in individual case reports $[3,4]-$ with exception of the Dens-axis fracture $[23,24]$. No fractures in the CS were discovered in the present examination.

Conspicuous findings are, compared to thoracic spine (TS) and lumbar spine (LS), the significantly higher BVF of the trabecular microarchitecture of CS.

Grote et al. [11] provide evidence that the CS differs from the other spinal column sections. In their study, they were able to show that the loss of bone volume with age is the least in the CS. Furthermore, no significant age-related loss of trabecular structural density was observed in the cervical vertebral body 3/4. The individual vertebral bodies of the CS show a difference in terms of their microarchitecture compared to the rest of the spinal column and therefore clearly occupies a special position of the individual movement segments. In contrast to Grote et al. [11], no histomorphometric but rather imaging evidence using micro-CT was obtained in this present examination. Methodologically comparable results are described in the case report by Schröder et al. [5] and in an article by Schober et al. [25]. Interesting in this context is the study by Acquaah et al. [26]. They already observed significantly lower BVF in the lumbar spine compared to the cervical spine during development at the age of 7 months, 1.2 and 2.5 years. The authors also compared their data on early bone development with the BVF data from literature. Their conclusion was that the loss of bone mass that occurs during the first year of life is never fully compensated. According to the authors, early development could therefore be important for the development of bone strength, but more likely due to structural changes in trabecular microarchitecture rather than bone mass itself. BVF was lowest in the over-80s group and significantly higher in all subgroups of the CS than in other spinal segments, which supports Acquaah et al. [26] conclusions. The decline in BVF with age for women and men [27] is similar. Chen et al. [28] assume after completion of their animal investigation that the BMD and BVF decreased from the cervical to lumbar spine. Cancellous bone of vertebra is metabolically more active than cortical bone and trabecular BMD may act as an initial predictor of spinal osteoporotic fracture [1]. Low BMD is correlated with increased fracture of the spine. Vertebral BMD decreases from cervical to lumbar spine, with the lowest BMD at the third lumbar vertebra [29].

Awareness of the different regional microstructural properties is of crucial importance for the assessment of age- and gender-related bone loss in vertebrae. This knowledge also provides better insights into the pathological mechanisms of spinal osteoporosis and the associated risk of fractures [30]. The risk of fractures is associated with age-related microdamage to trabecular bone-among other effects-which is partly caused by reduced BVF [31]. And BVF on the other hand is determined by Tb.N and Tb.Sp. Reduction of Tb.N in advanced age increases Tb.Sp [27]. Tb.N was significantly higher in the CS than in other spine sections. In the present study we found not only more but thicker trabecular bone in the cervical spine and the trabeculae were significantly closer to each other. This indicates the greater biomechanical competence of cervical vertebrae.

In general, the thickness of vertical struts in the trabecular bone of vertebrae is 100 to $200 \mu \mathrm{m}$, whereas the Tb.Sp of vertical trabeculae achieve 600 to $900 \mu \mathrm{m}$ [32-34]. At this point our values agree with already published data. In our investigation DA was significantly lower in the cervical spine than in other sections of the spine. The more anisotropic structure is caused by the worsening of trabecular architecture in vertebrae, which in turn means a greater tendency to fractures [32].

The significant difference between men and women is interesting in this context. The higher DA of men in the TS potentially explains their higher fracture risk in this area [2].

The data registered in the present investigation underline the specific features of the cervical spine. Reasons for these features must be determined in future investigations, especially regarding the greater bone density of the cervical spine and its morphological changes.

\section{Discussion of the method}

The puncture needle was selected on the basis of the data reported by Uhl et al. [35], who stated that the 8-G Jamshidi (Becton Dickinson GmbH, Heidelberg, Germany) needle is easy to use and also provides samples of good histological quality. Furthermore, biopsies obtained in animal experiments showed that a large drill specimen is useful for the 
assessment of trabecular bone volume, trabecular thickness, and the number of trabeculae [36].

The location of sample collection is very important for the interpretation. Chen et al. [27] and Gong et al. [37] report that the central and anterosuperior portions of the vertebral body have less BVF than the posterior portions. Banse et al. [33] also believe that the region with the least density is primarily located in the upper and anterior half of the vertebral body. Considering these facts, we obtained our samples from the center of the vertebral body and from the anterior aspect. It may be assumed that we sampled the structures with the lowest density in order to solve the question whether all structures of the vertebral column show rectified changes.

In summary osteoporosis is a major disease in aged women, increasing the risk for fractures accompanied by changes in the microarchitecture [38]. Further studies on non-osteoporotic spine should follow to evaluate changes in microarchitecture.

\section{Conclusions}

- BVF decreases from the cervical spine to the lumbar spine.

- Trabecular thickness and trabecular separation are different in the individual portions of the spine. The differences are especially pronounced between the cervical and thoracic spine and the cervical and lumbar spine.

- The degree of anisotropy is lower in the cervical spine than in the thoracic or lumbar spine.

\section{ORCID}

Guido Schröder: https://orcid.org/0000-0002-9953-3987

Benjamin Jabke: https://orcid.org/0000-0002-9647-0888

Marko Schulze: https://orcid.org/0000-0002-8189-811X

Andreas Wree: https://orcid.org/0000-0002-6446-0095

Heiner Martin: https://orcid.org/0000-0002-8104-8158

Olga Sahmel: https://orcid.org/0000-0003-3158-1066

Alexandra Doerell: https://orcid.org/0000-0003-2147-1613

Claus Maximilian Kullen:

https://orcid.org/0000-0001-6697-9408

Reimer Andresen: https://orcid.org/0000-0002-1575-525X

Hans-Christof Schober:

https://orcid.org/0000-0003-4901-6671

\section{Author Contributions}

Conceptualization: GS, AW, HM, RA, HCS. Data acquisition: BJ, MS, OS, CMK. Data analysis or interpretation: GS, RA, HM, HCS. Drafting of the manuscript: GS, MS, AD, CMK, RA, HCS. Critical revision of the manuscript: GS, CMK, RA, HCS. Approval of the final version of the manuscript: all authors.

\section{Conflicts of Interest}

No potential conflict of interest relevant to this article was reported.

\section{References}

1. Chen H, Kubo KY. Bone three-dimensional microstructural features of the common osteoporotic fracture sites. World J Orthop 2014;5:486-95.

2. Waterloo S, Ahmed LA, Center JR, Eisman JA, Morseth B, Nguyen ND, Nguyen T, Sogaard AJ, Emaus N. Prevalence of vertebral fractures in women and men in the population-based Tromsø Study. BMC Musculoskelet Disord 2012;13:3.

3. Ea HK, Weber AJ, Yon F, Lioté F. Osteoporotic fracture of the dens revealed by cervical manipulation. Joint Bone Spine 2004;71:246-50.

4. Ostrowski C, Ronan L, Sheridan R, Pearce V. An osteoporotic fracture mimicking cervical dystonia in idiopathic Parkinson's disease. Age Ageing 2013;42:658-9.

5. Schröder G, Wendig D, Jabke B, Schulze M, Wree A, Kundt G, Manhart J, Martin H, Sahmel O, Andresen R, Schober HC. [Comparison of the spongiosamorphology of the human cervical spine (CS), thoracic spine (TS) and lumbar spine (LS) of a 102-year-old body donor]. Osteologie 2019;28:283-8. German.

6. Benzel EC. Biomechanically relevant anatomy and material properties of the spine and associated elements. In: Benzel EC, editor. Biomechanics of Spine Stabilization: Principles and Clinical Practice. New York: McGraw-Hill; 1995.

7. Duval-Beaupère G, Robain G. Visualization on full spine radiographs of the anatomical connections of the centres of the segmental body mass supported by each vertebra and measured in vivo. Int Orthop 1987;11:261-9.

8. Kayser R, Beyer L. [Repetitorium manual medicine/chirotherapy]. Berlin: Springer; 2017. German.

9. Bühren V, Josten C. [Surgery of the injured spine: fractures, instabilities, deformities]. Berlin: Springer; 2013. German.

10. White AA, Panjabi MM. Clinical biomechanics of the spine. 2nd ed. Philadelphia: Lippincott; 1990.

11. Grote HJ, Amling M, Vogel M, Hahn M, Pösl M, Delling G. Intervertebral variation in trabecular microarchitecture throughout the normal spine in relation to age. Bone 1995;16:301-8. 
12. Yoganandan N, Pintar FA, Stemper BD, Baisden JL, Aktay R, Shender BS, Paskoff G, Laud P. Trabecular bone density of male human cervical and lumbar vertebrae. Bone 2006;39:336-44.

13. Gebauer M, Lohse C, Barvencik F, Pogoda P, Rueger JM, Püschel K, Amling M. Subdental synchondrosis and anatomy of the axis in aging: a histomorphometric study on 30 autopsy cases. Eur Spine J 2006;15:292-8.

14. Andresen R, Radmer S, Banzer D, Felsenberg D, Wolf KJ. [The quantitative determination of bone mineral content--a system comparison of similarly built computed tomographs]. Rofo 1994;160:260-5. German.

15. Genant HK, Wu CY, van Kuijk C, Nevitt MC. Vertebral fracture assessment using a semiquantitative technique. J Bone Miner Res 1993;8:1137-48.

16. Engelke K, Adams JE, Armbrecht G, Augat P, Bogado CE, Bouxsein ML, Felsenberg D, Ito M, Prevrhal S, Hans DB, Lewiecki EM. Clinical use of quantitative computed tomography and peripheral quantitative computed tomography in the management of osteoporosis in adults: the 2007 ISCD official positions. J Clin Densitom 2008;11:123-62.

17. Andresen R, Radmer S, Banzer D. Bone mineral density and spongiosa architecture in correlation to vertebral body insufficiency fractures. Acta Radiol 1998;39:538-42.

18. Christiansen BA, Bouxsein ML. Biomechanics of vertebral fractures and the vertebral fracture cascade. Curr Osteoporos Rep 2010;8:198-204.

19. Crilly RG, Cox L. A comparison of bone density and bone morphology between patients presenting with hip fractures, spinal fractures or a combination of the two. BMC Musculoskelet Disord 2013;14:68.

20. Intolo P, Milosavljevic S, Baxter DG, Carman AB, Pal P, Munn $J$. The effect of age on lumbar range of motion: a systematic review. Man Ther 2009;14:596-604.

21. Sullivan MS, Dickinson CE, Troup JD. The influence of age and gender on lumbar spine sagittal plane range of motion. A study of 1126 healthy subjects. Spine (Phila Pa 1976) 1994;19:682-6.

22. Dvorák J, Vajda EG, Grob D, Panjabi MM. Normal motion of the lumbar spine as related to age and gender. Eur Spine J 1995;4:18-23.

23. Ryan MD, Taylor TK. Odontoid fractures in the elderly. J Spinal Disord 1993;6:397-401.

24. Müller EJ, Wick M, Russe O, Muhr G. Management of odontoid fractures in the elderly. Eur Spine J 1999;8:360-5.

25. Schober HC, Boldt R, Jabke B, Spiegel S, Schulze M, Hornung A, Kolbe V, Andresen R, Kullen C, Martin H, Sahmel O, Schröder $\mathrm{G}$ Comparison of spongiosa morphology from human cervical spine, thoracic spine and lumbar spine of 10 human cadavar.
Eur Spine J 2019;28:2711-2.

26. Acquaah F, Robson Brown KA, Ahmed F, Jeffery N, Abel RL. Early trabecular development in human vertebrae: overproduction, constructive regression, and refinement. Front Endocrinol (Lausanne) 2015;6:67.

27. Chen H, Shoumura S, Emura S, Bunai Y. Regional variations of vertebral trabecular bone microstructure with age and gender. Osteoporos Int 2008;19:1473-83.

28. Chen H, Kubo KY. Segmental variations in trabecular bone density and microstructure of the spine in senescence-accelerated mouse (SAMP6): a murine model for senile osteoporosis. Exp Gerontol 2012;47:317-22.

29. Hayashi T, Chen H, Miyamoto K, Zhou X, Hara T, Yokoyama R, Kanematsu M, Hoshi H, Fujita H. Analysis of bone mineral density distribution at trabecular bones in thoracic and lumbar vertebrae using X-ray CT images. J Bone Miner Metab 2011;29:174-85.

30. Chen H, Zhou X, Fujita H, Onozuka M, Kubo KY. Age-related changes in trabecular and cortical bone microstructure. Int J Endocrinol 2013;2013:213234.

31. Follet H, Farlay D, Bala Y, Viguet-Carrin S, Gineyts E, BurtPichat B, Wegrzyn J, Delmas P, Boivin G, Chapurlat R. Determinants of microdamage in elderly human vertebral trabecular bone. PLoS One 2013;8:e55232.

32. McDonnell P, McHugh PE, O'Mahoney D. Vertebral osteoporosis and trabecular bone quality. Ann Biomed Eng 2007;35:170-89.

33. Banse X, Devogelaer JP, Munting E, Delloye C, Cornu O, Grynpas M. Inhomogeneity of human vertebral cancellous bone: systematic density and structure patterns inside the vertebral body. Bone 2001;28:563-71.

34. Mosekilde L. Age-related changes in vertebral trabecular bone architecture--assessed by a new method. Bone 1988;9:247-50.

35. Uhl M, Theves C, Geiger J, Kersten A, Strohm PC. [The percutaneous bone biopsy: in vitro study for comparison of bone biopsy needles]. Z Orthop Unfall 2009;147:327-33. German.

36. Park EA, Hong SH, Kim KG, Choi JY, Shin CS, Kang HS. Experimental bone biopsies using two bone biopsy needles: quantitative micro-CT analysis of bone specimens. Acad Radiol 2009;16:332-40.

37. Gong H, Zhang M, Yeung HY, Qin L. Regional variations in microstructural properties of vertebral trabeculae with aging. J Bone Miner Metab 2005;23:174-80.

38. Lee SH, Kim JN, Shin KJ, Koh KS, Song WC. Three-dimensional microstructures of the intracortical canals in the animal model of osteoporosis. Anat Cell Biol 2020;53:162-8. 